\title{
Dual X-Ray Photon Absorptiometry: Beyond the Bone Quantity?
}

\author{
F M Ulivieri* \\ Fondazione Irccs Cà Granda Policlinico, Italy
}

Submission: September 21, 2017 ; Published: September 25, 2017

*Corresponding author: F M Ulivieri, Fondazione Irccs Cà Granda Policlinico, Bone Metabolic Unit, Via F.Sforza 35, 20122 Milan, Italy, Tel: +300255033529; Email: ulivieri@gmail.com

\section{Opinion}

Osteoporosis is a characterized by low bone mass and microarchitectural deterioration, with a consequent increase in bone fragility [1]. Bone strength impairment leads to an increased risk of fracture, as strenght reflects the integration of bone quantity (bone mineral density, BMD) and bone quality [2]. Common sites of osteoporotic fractures are spine, hip, distal forearm and proximal homerus. These fractures determine high rates of disability and mortality: $50 \%$ of fracture-related deaths in women are due to hip fractures, $28 \%$ to clinical vertebral fractures and $22 \%$ to other fractures [1]. Twenty percent of hip fractured patients, die within the following year and $20 \%$ require permanent nursing home care $[3,4]$. Vertebral fractures are the most frequent fractures in osteoporotic patients, and are associated with substantial disability due to compromised spine dynamics and static biomechanics. Furthermore, their number and severity are related to an exponential increase of subsequent fractures [5].

The WHO gold standard method for the diagnosis of osteoporosis is the dual energy X-ray absorptiometry (DXA) [6], that allows to quantify BMD [7] that is directly correlated with an increase in fracture risk [1]. However, a relevant number of fragility fractures occur in the range of normal or slightly reduced BMD values [8], meaning that also qualitative aspects of bone, like bone architecture and bone geometry, play a role [9]. These bone structure aspects are, however, investigated by micro CT and histomorphometry and necessitate an invasive approach with a biopsy, usual taken at the iliac crest, not the typical site of fragility fractures.

New DXA tools recently developed, namely trabecular bone score (TBS) and hip structural analysis (HSA), obtained during DXA, can supply in formations about bone structure of spine and femur, respectively, in a not invasive way.

The first cited new DXA tools is the trabecular bone score (TBS), a gray-level textural measure that can be extracted from the 2-dimensional lumbar spine DXA image to estimate trabecular microstructure. TBS provides in-formations that are not captured by the standard BMD measurement [10]. The relationship between TBS texture and 3-dimensional microarchitecture parameters was documented by several ex vivo studies that reported significant correlations with the bone histology parameters defined by Parfitt (trabecular space and number, connective density); these correlations are independent from areal bone mineral density [11-15]. An elevated TBS value correlates with better skeletal texture, reflecting a better micro architecture. Recent studies demonstrated that TBS predicts fracture risk partially independently from BMD in primary and secondary osteoporosis and after pharmacological treatment [16-20]. However, nowadays a debate arouses about what TBS really represents and particularly about its true relation to vertebral strength [21,22].

TBS has been investigated also in the monitoring of pharmacological treatment of osteoporosis with evidence that it increases particularly with anabolic therapy, but the moderate entity of the amount, close to or even below the least significant change (LSC) of the measurement, does not suggest a use in clinical practice where physicians treat the single patient [23]. Noticeably, no data are available regarding changes of TBS and HSA after longer periods of treatment and no studies have investigated the relationship between TBS and HSA changes after anabolic agents and the reduction of fracture incidence, which is the real clinical goal of every pharmacological treatment of osteoporosis. It remains, therefore, an open question, if such a small increase in TBS, close to the LSC, results in an amelioration of bone quality able to determine a reduction of fracture rate [23].

The second cited DXA tools, HSA, similarly to BMD, was shown to relate independently to hip fracture risk [24]. The concentration of loading forces (stresses) is a function of bending moments and cross sectional geometry. Based on the principle described by Martin and Burr [25], a specific program for bone densitometry was developed, named Hip Structural Analysis (HSA), that derives the cross sectional geometry from images acquired by DXA. The main geometrical parameters, measured 
at narrow neck (NN), intertrochanter (IT) and femoral shaft (FS), are the bone surface area in the cross section (CSA) and the section modulus (Z), which are inversely related to maximum stresses due to axial and bending loads, respectively [26,27]. CSA is an index of resistance to axially directed compressive loads. $\mathrm{Z}$ is computed from the cross sectional moment of inertia (CSMI), which reflects the flexural strength being an index of rigidity. The ratio between the radius and the average cortical thickness provides a stability index of the cortex under compressive and bending loads (buckling ratio, BR).

Some works were published about HSA in osteoporosis and about bone quality variations after its pharmacological treatment [28]. After therapy, particularly with bone formation agents, changes in bone axial and bending strength and in cortical thickness are expected [23].

However, literatures to date do not allow to consider HSA as a reliable measure to predict fracture risk and to monitor pharmacological treatment for osteoporosis [28].

TBS and HSA are able to give additional information about bone strength that it is not supplied by BMD alone, although there is not unanimity of views, particularly about HSA. These parameters allow clinicians to better classify patients affected by a fragility fracture and to predict the risk of future fractures. TBS and HSA increase with anabolic therapy, but the moderate entity of the amount, close to or even below the LSC of the measurement, does not suggest a use in clinical practice where physicians treat the single patient.

Surely TBS and HSA have a special merit: having supplied to DXA not only an utility to the measurement of bone quantity, but even more for inquiring bone quality. Thus opening a new path to the promising evolutions of the dual X-ray photon absorptiometry.

\section{References}

1. Kanis JA, McCloskey EV, Johansson H, Cooper C, Rizzoli R, et al. (2013) European guidance for the diagnosis and management of osteoporosis in postmenopausal women. Osteoporos Int 24(1): 23-57.

2. Osteoporosis prevention diagnosis and therapy 2001. JAMA 285(6): 785-795.

3. Cooper C (1997) The crippling consequences of fractures and their impact on quality of life. Am J Med 103(2A): 12S-17S; discussion 17S-19S.

4. Cauley JA, Thompson DE, Ensrud KC, Scott JC, Black D (2000) Risk of mortality following clinical fractures. Osteoporos Int 11(7): 556-561.

5. Lindsay R, Silverman SL, Cooper C, Hanley DA, Barton I, et al. (2001) Risk of new vertebral fracture in the year following a fracture. JAMA 285(3): 320-323.

6. Cameron JR, Sorenson J (1963) measurement of bone mineral in vivo: an improved method. Science 142(3589): 230-232.

7. World Health Organ WHO Study Group (1994) Assessment of fracture risk and its application to screening for postmenopausal osteoporosis. Tech Rep Ser 843: 1-129.
8. Hordon LD, Raisi M, Aaron JE, Paxton SK, Beneton M, et al. (2000) Trabecular architecture in women and men of similar bone mass with and without vertebral fracture: I. Two-dimensional histology. Bone 27(2): 271-276.

9. Link TM, Majumdar S (2004) Current diagnostic techniques in the evaluation of bone architecture. Curr Osteoporos Rep 2(2): 47-52.

10. Hans D, Barthe N, Boutroy S, Pothuaud L, Winzenrieth R, et al. (2011) Correlations between trabecular bone score, measured using anteroposterior dual-energy X-ray absorptiometry acquisition, and 3-dimensional parameters of bone microarchitecture: an experimental study on human cadaver vertebrae. J Clin Densitom 14(3): 302-312.

11. Pothuaud L, Carceller P, Hans D (2008) Correlations between grey-level variations in 2D projection images (TBS) and 3D microarchitecture: applications in the study of human trabecular bone microarchitecture. Bone 42: 775-787.

12. Hans D, Goertzen AL, Krieg MA, Leslie WD (2011) Bone microarchitecture assessed by TBS predicts osteoporotic fractures independent of bone density: the Manitoba study. J Bone Miner Res 26(11): 2762-2769.

13. Winzenrieth R, Michelet F, Hans D (2013) Three-dimensional (3D) microarchitecture correlations with 2D projection image gray-level variations assessed by trabecular bone score using high-resolution computed tomographic acquisitions: effects of resolution and noise. J Clin Densitom 16(3): 287-296.

14. Roux JP, Wegrzyn J, Boutroy S, Bouxsein ML, Hans D, et al. (2013) The predictive value of trabecular bone score (TBS) on whole lumbar vertebrae mechanics: an ex vivo study. Osteoporos Int 24(9): 24552460.

15. Muschitz C, Kocijan R, Haschka J, Pahr D, Kaider A, et al. (2015) TBS reflects trabecular microarchitecture in premenopausal women and men with idiopathic osteoporosis and low-traumatic fractures. Bone 79: 259-266.

16. Silva BC, Leslie WD, Resch H, Lamy O, Lesnyak O, et al. (2014) Trabecular bone score: a noninvasive analytical method based upon the DXA image. J Bone Miner Res 29(3): 518-530.

17. Popp AW, Meer S, Krieg MA, Perrelet R, Hans D, et al. (2016) Bone mineral density (BMD) and vertebral trabecular bone score (TBS) for the identification of elderly women at high risk for fracture: the SEMOF cohort study. Eur Spine J 25(11): 3432-3438.

18. Harvey NC, Glüer CC, Binkley N, McCloskey E V, Brandi ML, et al. (2015) Trabecular bone score (TBS) as a new complementary approach for osteoporosis evaluation in clinical practice. Bone 78: 216-224.

19. Iki M, Tamaki J, Kadowaki E, Sato Y, Dongmei N, et al. (2014) Trabecular bone score (TBS) predicts vertebral fractures in Japanese women over 10 years independently of bone density and prevalent vertebral deformity: The Japanese population-based osteoporosis (JPOS) cohort study. J Bone Miner Res 29(2): 399-407.

20. Ulivieri FM, Silva BC, Sardanelli F, Hans D, Bilezikian JP, et al. (2014) Utility of the trabecular bone score (TBS) in secondary osteoporosis. Endocrine 47(2): 435-448.

21. Maquer G, Lu Y, Dall'Ara E, Chevalier Y, Krause M, et al. (2016) The Initial Slope of the Variogram, Foundation of the Trabecular Bone Score, Is Not or Poorly Associated With Vertebral Strength. J Bone Miner Res 31(2): 341-346.

22. Bousson V, Bergot C, Sutter B, Thomas T, Bendavid S, et al. (2015) Trabecular Bone Score: Where are we now? Joint Bone Spine 82(5): 320-325.

23. Ulivieri FM, Caudarella R, Camisasca M, Cabrini DM, Merli I, et al. (2016) Assessment of bone quality in osteoporosis treatment with bone anabolic agents: Really something new? Curr Rheumatol Rev. 


\section{Current Trends in Clinical \& Medical Imaging}

24. Crabtree N, Lunt M, Holt G, Kröger H, Burger H, et al. (2000) Hip geometry, bone mineral distribution, and bone strength in European men and women: the EPOS study. Bone 27: 151-159.

25. Martin RB, Burr DB (1984) Non-invasive measurement of long bone cross-sectional moment of inertia by photon absorptiometry. J Biomech 17(3): 195-201.

26. Danielson ME, Beck TJ, Karlamangla AS, Greendale GA, Atkinson EJ, et al. (2013) A comparison of DXA and CT based methods for estimating the strength of the femoral neck in post-menopausal women. Osteoporos Int 24(4): 1379-1388.
27. Ramamurthi K, Ahmad O, Engelke K, Taylor RH, Zhu K, et al. (2012) An in vivo comparison of hip structure analysis (HSA) with measurements obtained by QCT. Osteoporos Int 23(2): 543-551.

28. Broy SB, Cauley JA, Lewiecki ME, Schousboe JT, Shepherd JA, et al (2015) Fracture Risk Prediction by Non-BMD DXA Measures: the 2015 ISCD Official Positions Part 1: Hip Geometry. J Clin Densitom 18(3): 287-308.

\section{Your next submission with Juniper Publishers} will reach you the below assets

- Quality Editorial service

- Swift Peer Review

- Reprints availability

- E-prints Service

- Manuscript Podcast for convenient understanding

- Global attainment for your research

- Manuscript accessibility in different formats

( Pdf, E-pub, Full Text, Audio)

- Unceasing customer service

Track the below URL for one-step submission https://juniperpublishers.com/online-submission.php 